\title{
SECTORAL STRUCTURE OF THE REGIONAL ECONOMIC COMPLEX: INVESTMENT COMPONENT
}

\author{
Tatiana Chechetova-Terashvili ${ }^{1}$, Natalia Chechetova ${ }^{2}$, Joanna Stuglyk ${ }^{3}$ \\ ${ }^{I}$ Doctor of Science (Economics), Associate Professor, Simon Kuznets Kharkiv National University of Economics, \\ Kharkiv, Ukraine, e-mail: docha@ pisem.net, ORCID: https://orcid.org/0000-0002-5217-9255 \\ ${ }^{2}$ Doctor of Science (Economics), Professor, O.M. Beketov National University of Municipal Economy, Kharkiv, \\ Ukraine, e-mail: nchechetova@ukr.net, ORCID: https://orcid.org/0000-0003-1988-2923 \\ ${ }^{3}$ Ph.D. in Economics, Taurida National University named after V.I. Vernadsky, Kiev, Ukraine, e-mail: \\ crimea.tnu@gmail.com,ORCID: https://orcid.org/0000-0003-3726-9452
}

Citation:

Chechetova-Terashvili, T., Chechetova, N., \& Stuglyk, J. (2020). Sectoral structure of the regional economic complex: investment component. Economics, Finance and Management Review, (2), 10-15. https://doi.org/10.36690/2674-52082020-2-10

Received: April 20, 2020

Approved: May 19, 2020

Published: June 05, 2020

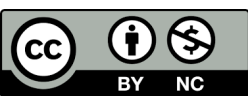

This article is an open access article distributed under the terms and conditions of the Creative Commons Attribution (CC BY-NC 4.0) license
Abstract. The article considers the main approaches to the definition of a regional economic complex. The paper analyzes a wide range of indicators that are the subject of analysis and assessments in the long-term planning and forecasting of development indicators of the regional economic complex. The paper substantiates, both in theoretical and methodological, and practical plans, the use of a systematic approach, which involves the allocation of internal and external components of the regional economic space. The main functions that perform the external and internal components of the economic space are analyzed. The main approaches to determining the structure of the economic system are investigated. The traditional criteria that determine the classification of economic entities to a specific industry are highlighted. The principles of sectoral (sectoral) classification of regional economic systems are considered. The author substantiates the statement that to manage the development of the regional economic complex and bring it to the path of sustainable development, a three-sector model of the economy can be applied and its main components are presented.

Keywords: region, economic complex, economic system, structure, industry, sector.

JEL classification: $R 12, R 58$

Formulas: 0; fig.: 0; tabl.: 0; bibl.: 5

Introduction. The structural-dynamic approach and the theory of structural dynamics investigate specific quantitative relationships of structural and dynamic aspects of the development of economic systems on actual material using measures of dynamics and structural changes in economic aggregates.

The regional economic complex (REC) is characterized by hierarchical management and the activity of its individual subsystems. It has a complex internal structure, the interaction of the elements of which is determined by formally defined relationships (for example, the existing industry structure). From this point of view, the REC is presented as a purposeful and multi-purpose system with heterogeneous internal and external goals, independent subgoals of individual subsystems, a system of indicators for measuring goals, diverse strategies for achieving them, etc.

Under the current conditions, the foundation for creating comprehensive programs for the planned development of the region is the assessment of the joint dynamics of the structural and volumetric parameters of the functioning of the sectors of the regional economy, which will reveal the patterns of their development and determine the targeted proactive effect.

Thus, a study aimed at developing a single concept for managing the regional economy from the standpoint of a structurally dynamic approach and improving the system for managing regional development is relevant. 
Literature review. The economic structure and problems of improving structural policy are studied by domestic and foreign scientists, including O.I. Aptekar, V.V. Bila, V. Geets, I.V. Kryuchkova, O.A.Volynets, O.A. Lebedeva, E. Libanova, A.F. Melnik, A.A. Pavlyuk, L.V.Shinkaruk and others. Despite the growing interest of scientists in the chosen subject area for research, many fundamental issues have so far only been identified, but not resolved, including those related to the formation of the sectoral structure of the regional economic complex, and the development of a methodology for studying the dynamics of the development of REC.

Aims. The purpose of the article is to explore the theoretical and methodological foundations of the sectoral (sectoral) structure of regional economic systems.

Methods. The author used the methods of static and logical comparison, systematization and generalization, which made it possible to achieve the goal of the study.

Results.. A regional economic complex is a combination of a large number of economic entities of various types of activity. They can closely interact with each other at the stages of production and circulation of goods and services, but they can function almost isolated in the technological process, interacting only indirectly, for example, through a common infrastructure.

Ensuring sustainable economic development has always been and remains a key task of the state. High rates of economic growth create the necessary potential for realizing national interests and meeting the needs of society, for ensuring its development in all areas corresponding to the chosen goals. Economic growth in modern conditions is considered not only quantitatively, but also qualitatively. Therefore, the problem of economic growth should be closely linked to structural problems. Forecasting long-term economic development trends and building strategic plans are the basic tasks of any state.

Long-term planning and forecasting of REC indicators must take into account the complexity of the factors that influence this growth. The subject of analysis and evaluation is a wide range of indicators, namely:

- the scale and pace of GDP growth;

- The resource base for economic development is investment;

- the effectiveness of the national economy;

- price dynamics and inflation parameters;

- financial base for development;

- parameters reflecting the foreign economic situation of a country or region.

It is obvious that all these indicators are dependent on measuring the economic product and measuring the costs of resources. The scale of the economy and its dynamics are usually estimated on the basis of indicators of GDP (GRP).

All business processes in the region proceed within a certain spatial framework, so it is rational, from our point of view, to study both the theoretical, methodological and practical plans, using a systematic approach, which involves the allocation of internal and external components of the regional economic space. Each of these components of the economic space of the region performs certain functions. 

provides:

So, the external economic space of the functioning of the regional economy

1) the organic relationship of the regional economy with other regions and the country as a whole;

2) the formation of reproduction resources created in the process of exchange;

3) the formation of the natural-material structure of products to be exported to other areas, taking into account the capacity of national and regional markets.

The functioning of the external economic space allows each regional system to take full advantage of the territorial division of labor, common principles for the distribution of productive forces, and general rules for regulating monetary circulation and financial and credit relations.

Internal economic space is, first of all, elements of the economic potential located in the region that make up the material and material and technical basis of the regional reproduction process [1].

Before analyzing the internal space of a regional economy, the following remark should be made. The functional representation of a particular system is inextricably linked with its structure, since the latter describes a set of stable connections of an object, ensuring its integrity and identity to itself, preservation of the basic properties with various internal and external changes.

The structural method of analysis of a regional economy should not be reduced only to determining its elemental composition. Structuralism in the broadest sense, as an abstract-theoretical research method, suggests the possibility of modeling, formalizing and mathematizing a system selected as an object of study. The choice of system structure always contains the possibility of variation.

The general theory of systems and system analysis defines the structure as a set of stable system connections ensuring the preservation of its basic properties under various external and internal changes. The composition of the elements, their general organization, method of connection, spatial location, etc., are associated with the concept of system structure. A change in the structure of the system consists in a change in the parts and interconnections between the parts, which can be accompanied by a change in their number and leads to a qualitative transformation of the system. Thus, the structure is one of the main characteristics of the development of the system, since the process of its development is closely related to qualitative changes [2].

Currently, in the economic literature there is no unambiguous representation of the structure of the economic system, which is mainly due to the lack of a unified interpretation of the very object of structuring.

In his monograph Blyakhman L.S. interprets the structure of the economy as a structure, a set of relations, parts and elements that make up a certain economic whole. The structure reflects the form of arrangement of elements and the nature of the interaction of their sides and properties, this is the result of the movement of elements of the system, the result of their organization, ordering. In turn, the elements of the system consist of parts that, at a certain level of consideration, possess all system attributes. Thus, we can speak both about the structure of the economy as a 
whole and about the structure of its constituent parts, that is, about the macro- and microstructure [3, p. 118].

According to Zotov V.V. The internal economic space of the region as an economic complex combines a number of parameters [4]:

- elements of production potential located in the region that make up the material basis of the regional economy;

- the natural environment of life and the course of production processes;

- structural elements of the regional system;

- a set of interacting institutional actors;

- technical and technological structure of business processes;

- a system of regional clusters that are currently forming the bulk of economic ties between regional entities;

- regional economic mechanism;

- the cultural environment of the society, ensuring the susceptibility of the regional community to the dissemination of standards of quality of life and innovations in reproduction.

In the context of the globalization of the economy, REC is understood not as a spatially limited form of territorial formation, but as an independent spatially localized community based on the unity of economic relations, having a single economic base capable of sustainable development, and includes economic clusters vertically and horizontally interacting between the internal and external systems in the process of social reproduction.

The principles of sectoral (sectoral) classification are based on the concept of an industry (type of activity) as an element of REC. Branches are groups of business entities of various organizational and legal forms that are homogeneous by a certain qualitative characteristic and are characterized by specific production conditions in the system of social division of labor.

As traditional criteria for determining the classification of business entities as a specific industry, the authors distinguish the following:

- the purpose of the product or service;

- type of basic raw materials and materials, other factors of creating the result (product, service);

- features of the process of creating a product or service, expressed, inter alia, in terms of the duration of the operating cycle and asset turnover characterizing the inertia of the industry.

For the purposes of industry analysis of the mesoeconomic system at the first stage of the study, it is rational to divide the industries into two areas, traditional for classical foreign and domestic economic theory, the production sector and the service sector.

Discussion. I would like to pay a special attention to the system of regional clusters - a set of interconnected market formations of various types that ensure the effective development and functioning of the regional economic complex. The system of regional clusters includes the consumer market, the market for means of production, the labor market, the market for financial and credit resources and 
securities, the real estate market, and the market for information and knowledge.

All clusters participate in the circulation of material, financial, credit and cash flows, while regulating economic relations between the entities of REC in order to ensure continuity and balance in the development of productive forces and production relations.

Regional markets are interconnected with each other and with the external environment. In accordance with the functional purpose, regional markets can be divided into three groups:

1) a cluster of markets directly or indirectly affecting the material security of the population and living standards (consumer market, labor market, information and knowledge market, real estate market, financial market);

2) a cluster of markets associated with the formation of material and material flows in the region and ensuring the reproduction of elements of productive forces (market: labor, the market of means of production, the market of information and knowledge);

3 ) a cluster of markets that performs the functions of a cross-cutting service character (information and knowledge market, financial market).

All regional clusters consisting of the above markets are interconnected and interact in the direction of realizing the interests of the subjects of the regional economic complex and forming the prerequisites for sustainable and balanced regional development.

The sustainable development of the REC is a consequence of the differentiation and integration of its elements and depends on the degree of development of the social division of labor, forms of ownership of the means of production and on the effectiveness of the public administration system at the mesoscale.

All forms of differentiation of production can be reduced to two groups: 1) vertical differentiation, which provides for the separation of independent industries and industries, and 2) horizontal, associated with the formation on the territory of the country of specialized territorial-production formations, such as industrial units, territorial-production complexes.

To manage the development of the REC and bring it to the path of sustainable development, a three-sector model of the economy can be used. Three-sector economy: the zero (material) sector produces objects of labor; the first (capitalcreating) - means of labor; the second (consumer) - consumer goods. The material sector occupies a special intermediate position between the capital-creating and consumer sectors: in a certain respect, its behavior is similar to that of the consumer sector, although it is related to the capital-creating sector by purpose. It is assumed that each sector has fixed production assets, while labor and investment can move freely between sectors [5, p. 83].

Currently, scientists are exploring the possibility of using a stratified classification of the economy. A stratified classification is based on elements called strata. Each stratum has its own characteristics, laws and principles that characterize the system as a whole and the processes occurring in it. In the regional economy, strata can be considered a set of industries (types of economic activity) or territorial elements (municipalities), economic processes, etc. 
Stratification of REC allows us to study the evolutionary dynamics of the transformation of economic elements and to regulate their "movement" to achieve the desired state. The evolutionary movement of structural elements causes correspondingly different rates of change in activities.

Conclusions. The formation of the sectoral structure of the REC makes it possible to streamline the regional management system according to the subject principle and to regulate the development dynamics of individual sectors to achieve the desired state of the REC in general.

In carrying out practical calculations and forecasts, the researcher often resorts to grouping existing activities into sectors for the convenience of working with a wide range of information.

The sectoral structure of the RHC is built depending on the nature of the functioning of economic entities and their role in the development of the region:

- subsidized sector (activities related to solving social problems of regional development and which are significantly dependent on state funding);

- investment sector (activities attractive to private investors, the implementation of which requires significant financial injections for further development);

- the donor sector (areas of activity related to increased exploitation of natural raw materials, which do not require significant state funding and are a source of development for the regional economic system);

- self-sufficient sector (a range of infrastructure enterprises operating on the principles of self-sufficiency), the content of which varies depending on the specifics of each particular region and the general level of its socio-economic development.

The filling of REC sectors varies depending on the specifics of each particular region and the general level of its socio-economic development. The formation of the sectoral structure of the REC makes it possible to streamline the regional management system according to the subject principle and to regulate the development dynamics of individual sectors to achieve the desired state of the REC in general.

Author contributions. The authors contributed equally.

Disclosure statement. The authors do not have any conflict of interest. References:

1. Dynkina, A.L. and Ivanova, N.I. (2008), Innovative Economics, Pan Books, Moscow.

2. Abuzyarova, M.I. (2011), "Methodological foundations of structural changes in the economy", Economics and Management, №. 4 (77), pp. 181-185.

3. Blyakhman, L.S. (2011), Three colors of economic time: achievements and problems of the economy, textbook, CPI SGUTD, $247 \mathrm{p}$.

4. Zotov, V.V. Presnyakov, V.F. and Rosenthal, V.O. (2016), "Institutional problems of the functioning and transformation of the Russian economy", Economic science of modern Russia, №. 35, pp. 34-39.

5. Kuzbozhev, E.N. and Samofalova, E.V. (2016), Management of the structural dynamics of the region's economy, monograph, Kursk, $136 \mathrm{p}$. 